\title{
Mudança na estrutura produtiva do Médio Paraíba- RJ: uma análise a partir das perspectivas de variedade (não)relacionada e complexidade econômica
}

Change in the productive structure of the "Médio Paraíba-RJ": An analysis from the (un)related variety and economic complexity

Cambio en la estructura productiva del "Médio Paraíba-RJ": Un análisis desde la perspectiva de variedad (no) relacionada y complejidad económica

Èvolution de la structure productive du "Médio Paraiba-RJ": une analyse du point de vue de la variété (non)liée et de la complexité économique

Bianca Louzada Xavier Vasconcellos, Guilherme de Oliveira Santos , Renata Lèbre La Rovere, Robson Dias da Silva e Vinicius Layter Xavier

\section{OpenEdition}

\section{Journals}

Edição electrónica

URL: https://journals.openedition.org/espacoeconomia/20792

DOI: 10.4000/espacoeconomia.20792

ISSN: 2317-7837

Editora

Núcleo de Pesquisa Espaço \& Economia

\section{Refêrencia eletrónica}

Bianca Louzada Xavier Vasconcellos, Guilherme de Oliveira Santos, Renata Lèbre La Rovere, Robson Dias da Silva e Vinicius Layter Xavier, «Mudança na estrutura produtiva do Médio Paraíba-RJ: uma análise a partir das perspectivas de variedade (não)relacionada e complexidade econômica», Espaço e Economia [Online], 22 | 2021, posto online no dia 09 janeiro 2022, consultado o 11 agosto 2022. URL: http://journals.openedition.org/espacoeconomia/20792 ; DOI: https://doi.org/10.4000/ espacoeconomia.20792

Este documento foi criado de forma automática no dia 11 agosto 2022

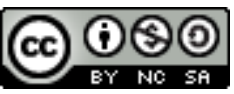

Creative Commons - Atribuição-NãoComercial-Compartilhalgual 4.0 Internacional - CC BY-NC-SA 4.0 https://creativecommons.org/licenses/by-nc-sa/4.0/ 


\section{Mudança na estrutura produtiva do Médio Paraíba-RJ: uma análise a partir das perspectivas de variedade (não)relacionada e complexidade econômica}

Change in the productive structure of the "Médio Paraíba-RJ": An analysis from the (un)related variety and economic complexity

Cambio en la estructura productiva del "Médio Paraíba-RJ": Un análisis desde la perspectiva de variedad (no) relacionada y complejidad económica

Èvolution de la structure productive du "Médio Paraiba-RJ": une analyse du point de vue de la variété (non)liée et de la complexité économique

Bianca Louzada Xavier Vasconcellos, Guilherme de Oliveira Santos, Renata Lèbre La Rovere, Robson Dias da Silva e Vinicius Layter Xavier

NOTA DO AUTOR

O presente trabalho foi realizado com apoio da Coordenação de Aperfeiçoamento de Pessoal de Nível Superior - Brasil (CAPES) - Código de Financiamento 001

\section{Introdução}

Não obstante o aumento da importância do setor de serviços, a indústria manufatureira ainda se encontra em posição central na determinação do crescimento da economia global e, por conseguinte, na estruturação produtiva e urbana regional. Ao mesmo tempo, ainda que as condicionantes do desenvolvimento internacional estejam 
sustentadas sobre a chamada globalização, é notável a permanência e, em certo sentido, o fortalecimento das escalas local e regional enquanto espaços vitais para as interações e articulações entre os diversos atores, grupos e classes - estado, firmas, trabalhadores, instituições -, e onde, consequentemente, o conhecimento se faz expandido.

2 Na porção meridional do Estado do Rio de Janeiro se localiza a microrregião do Médio Paraíba-RJ, reconhecida por abrigar um polo metalomecânico e automotivo que encabeçam a estrutura produtiva regional, sendo responsáveis por parcela significativa do emprego e da renda locais. Nos últimos quinze anos, estudiosos têm debatido sobre as oportunidades e desafios que a região enfrenta em relação a concentração desses segmentos produtivos ${ }^{1}$, seu papel no desenvolvimento local e também sobre uma suposta alta dependência em relação aos mesmos.

3 Para entendermos melhor essas questões, buscamos no campo da Geografia Econômica Evolucionária a ideia de variedade relacionada e variedade não relacionada, conceitos que buscam explicar o quanto setores industriais são relacionados ou não relacionados (FRENKEN, OORT e VERBURG, 2007), além de mensurar em que medida o conhecimento produtivo das empresas de determinada região podem ter similaridades em relação às suas capacidades/competências, seja em nível tecnológico, laboral ou produtivo. Vale alertar que não há métrica única para calcular a variedade (não)relacionada, que tem por finalidade entender os processos que geram inovações incrementais ou radicais, e, consequentemente, o crescimento econômico das regiões.

4 No entanto, apenas conhecer em que medida os segmentos industriais estão ou não relacionados poderia ser insuficiente para fornecer uma boa resposta, ou um "melhor caminho", para proposição de políticas públicas mais eficazes para o crescimento econômico da região. Por isso, incorporamos à análise a dimensão da complexidade econômica. Os trabalhos desenvolvidos por Hidalgo e Hausmann (2009) e Hausmann et al. (2013) corroboram empiricamente a ideia ${ }^{2}$ de que a indústria não apenas importa para o crescimento econômico, como pode representar e determinar a trajetória do crescimento econômico de um "lugar". A abordagem da complexidade econômica utiliza dados do comércio internacional para revelar características da estrutura produtiva. O tipo de produto que cada lugar produz e exporta faz diferença, uma vez que os produtos mais complexos demandam maior quantidade de diferentes capacidades, que são difíceis de serem reproduzidas em outros lugares. Essas capacidades são desenvolvidas ao logo do tempo, de acordo com a trajetória e as especificidades de cada lugar. A diversificação produtiva, portanto, é importante e desejada, tanto para a abordagem da Geografia Econômica Evolucionária, quanto para a abordagem da complexidade econômica. Nesse sentido, as abordagens são convergentes e, por isso, serão analisadas conjuntamente.

5 Com base nestas reflexões e conceitos, o presente artigo tem como objetivo principal analisar as mudanças recentes da estrutura produtiva da Região do Médio-Paraíba-RJ (RMP-RJ) sob a ótica da variedade (não)relacionada e da complexidade econômica. Busca-se entender, portanto, os significados dessas recentes mudanças e quais as possíveis tendências podem ser observadas. Importante registrar que as abordagens propostas entendem que a diversificação produtiva, mais especificamente a diversificação relacionada, é o melhor caminho para o desenvolvimento. Essa ideia também converge com o trabalho seminal de Jane Jacobs (1969), ao considerar que a diversificação pode amortecer choques econômicos e gerar empregos (FRENKEN; OORT; VERBURG, 2007; MAMELI; IAMMARINO; BOSCHMA, 2012; WIXE; ANDERSSON, 2017). 
6 Para tanto, o trabalho está dividido em cinco seções, além dessa introdução. A seção 2 apresenta os pilares teóricos do trabalho. Na terceira seção é descrito um panorama geral sobre a região do Médio Paraíba. A quarta seção detalha a metodologia. Na quinta seção é feita a discussão dos resultados, e, por fim, a última seção traz a conclusão, onde são sumarizados os principais achados, as limitações e as questões de pesquisa futuras.

\section{Indústria, variedade (não) relacionada e complexidade econômica}

\section{Indústria e desenvolvimento}

7 Com a revolução industrial inglesa, a indústria manufatureira passou a ser entendida como o pilar do crescimento econômico. Adam Smith (1983 [1776]), por exemplo, afirma que a origem da riqueza de uma nação se assenta na divisão do trabalho, por essa possibilitar aumento da produtividade e a criação e ampliação de mercados, e aponta que a divisão do trabalho tende a ser mais profunda na manufatura. Por isso, em sua visão as capacidades de geração de riqueza, emprego e bem-estar estariam mais visíveis no seio da indústria, comparativamente à agricultura tradicional ou ao simples comércio de bens. Outro autor clássico que destacou o peso e papel da indústria para dinâmica econômica foi Marx (2017 [1872]). A grande manufatura foi objeto de minuciosa atenção do autor, para o qual estava nela a chave para a compreensão do sistema moderno, notadamente as formas de organização e disciplina laboral, de origem do valor e do circuito de reprodução ampliada do que ele chamava modo de produção capitalista.

No imediato pós-segunda guerra, ganhou urgência o debate sobre desenvolvimento e reconstrução, notadamente das regiões diretamente atingidas pelo conflito bélico, mas também das regiões consideradas menos desenvolvidas do ponto de vista econômico. Dentro de um contexto internacional de acirramento entre duas superpotências, com projetos políticos e econômicos totalmente antagônicos, observou-se que a indústria não apenas mantinha, como ampliava seu papel de motor econômico, se fortalecendo e ampliando a fronteira de produção setorial através de esforço cada vez mais sistematizado de pesquisa e inovação. O salto tecnológico observado durante a guerra fria é em grande medida tributário desse processo, e possibilitaria décadas adiante as mudanças no paradigma tecno-econômico sob o signo da globalização econômica (Pérez, 2010).

9 Na América Latina, em geral, e no Brasil, em particular, processos de industrialização fomentaram mudanças significativas. Esses processos em muito seguiram os avanços do campo chamado "economia do desenvolvimento", um conjunto teórico formado por autores que buscavam entender e formular propostas e estratégias de desenvolvimento para aquelas nações e regiões nas quais os níveis de renda per capita e produtividade do trabalho se mantinha muito abaixo da média das nações "ricas". Tanto os "teóricos do desenvolvimento" filiados ao Departamento de Assuntos Econômicos das Nações Unidas, quanto os economistas da Comissão Econômica para a América Latina e o Caribe (CEPAL), entendiam que o investimento ampliado em indústria se fazia necessário para a melhoria do conjunto econômico desses países. Dessa forma, planos e programas de desenvolvimento econômico baseados em investimentos em setoreschave da indústria foram postos em ação ao longo de três décadas (1950, 1960, 1970), como forma de promoção do desenvolvimento. 
10 As graves crise, econômica e política, sofridas pela América Latina durante os anos 1980 e 1990 fizeram com que muito dessas tentativas de desenvolvimento via industrialização fossem paralisadas e/ou abandonadas. Essa situação se deu em quadro de grave crise fiscal, monetária e externa, aliada às lutas por redemocratização nas principais economias do subcontinente. A partir dos anos 1980, observou-se uma retomada das estratégias de desenvolvimento baseadas em "vantagens comparativas" regionais, mais precisamente, ancoradas no uso dos fatores de produção mais abundantes e baratos (recursos naturais e mão de obra) com vistas à produção de bens primários para a exportação.

11 Em certo sentido, essa reorientação neoprimário-exportadora se deu como boia de salvação, porém também como aceitação passiva de novo redesenho do mapa global da produção, dado que a China já se apresentava ali como "a nova fábrica" do mundo. Isso ensejou um processo de desindustrialização precoce da economia brasileira (Ricupero 2014, Feijó \& Oreiro, 2010), que afetou a dinâmica do mercado de trabalho e do crescimento nacional, assim como trouxe desafios e pressões à escala subnacional.

12 Nesse contexto, a Região do Médio Paraíba-RJ se destaca enquanto região industrializada a manter sua estrutura industrial e, ainda, conseguir atrair investimentos, sobretudo durante o período conhecido por Guerra Fiscal. Em que pese os deletérios efeitos para o conjunto nacional dessa "guerra", para os municípios da região em questão esse período permitiu a incorporação de novas plantas produtivas e certo espraiamento da produção para fora do eixo Volta Redonda-Barra Mansa.

\section{Relatedness, Variedade Relacionada e Variedade não Relacionada}

13 O conceito de grau de relacionamento (relatedness), desenvolvido pela Geografia Econômica Evolucionária no âmbito do debate sobre diversificação regional, se ancora na ideia de que o conhecimento possui uma arquitetura que é baseada em similaridades e diferenças, possibilitando a utilização de diversos tipos de conhecimento. Argumentase, portanto, que o conhecimento transborda de forma mais intensa quando as regiões são compostas por indústrias relacionadas que compartilham uma base de conhecimento similar. Mais especificamente, defende-se que as regiões necessitam de variedade relacionada (related variety) no intuito de favorecer a transferência efetiva de conhecimento entre setores diferentes (porém relacionados), e estimular a recombinação de "blocos de conhecimento" (pieces of knowledge) de maneiras totalmente novas (Boschma, 2009). Além disso, quanto maior o número de setores tecnologicamente relacionados em uma região (i. e., maior o grau de variedade em setores relacionados), maior é a disponibilidade de oportunidades de aprendizado, e, consequentemente, mais transbordamentos de conhecimento são esperados de ocorrer, impulsionando o desenvolvimento regional.

Em síntese, a variedade relacionada é um conceito que articula os transbordamentos de conhecimento à renovação econômica, novas trajetórias de crescimento e desenvolvimento regional. Isto implica que o desenvolvimento das regiões no longo prazo depende de sua habilidade em se diversificar em novas aplicações e novos setores enquanto se alicerçam em sua atual base de conhecimento e competências (Asheim et al., 2011). A variedade relacionada impulsiona o processo de ramificação econômica nas regiões através de três mecanismos: dinâmicas de spinoff, mobilidade de mão-de-obra e formação de redes. Posto que tais mecanismos transferem conhecimento ao longo de 
setores e, principalmente, entre antigos e novos setores no nível regional, os mesmos contribuem para o sucesso do processo de diversificação regional.

Mais recentemente, os geógrafos econômicos evolucionários começaram a dar mais atenção às possibilidades de geração de inovações e diversificação regional a partir da variedade não-relacionada (unrelated variety) (Boschma e Frenken, 2017). Grosso modo, a variedade não-relacionada compreende setores baseados em conhecimentos não semelhantes (dissimilar) e ancorados em domínios institucionais diferentes, tornando-os indubitavelmente pouco adequados a processos de aprendizado e troca de conhecimento intersetoriais (Grillitsch et al., 2018).

Entretanto, a literatura aponta que também é possível transformar "peças" de conhecimento que anteriormente eram tidas como não-relacionadas em relacionadas na forma de artefatos ou serviços que abrem caminho para futuras inovações (Castaldi et al., 2015). Neste prisma, apesar das inovações resultantes da recombinação de domínios previamente não-relacionados terem maior probabilidade de falhar, elas possuem ao mesmo tempo mais chance de serem radicais, podendo criar aplicações, funcionalidades e princípios operacionais completamente novos (Saviotti e Frenken, 2008). Deste modo, a oposição entre variedade relacionada e não-relacionada pode ser enganosa, levando em consideração que ambos os tipos de variedade podem levar à inovação. Por um lado, a variedade relacionada pode aumentar a probabilidade de inovações em geral, e, por outro, a variedade não-relacionada é capaz de aumentar a probabilidade de inovações disruptivas, que são raras (Castaldi et al., 2015).

Neste diapasão, Saviotti e Frenken (2008) argumentam que a diversificação baseada na variedade não-relacionada é relevante para evitar lock-ins regionais e assegurar vantagens competitivas de longo-prazo. Pinheiro et al. (2018), por seu turno, apontam que a variedade não-relacionada protege melhor as regiões contra choques assimétricos externos na demanda e contra o aumento do desemprego.

Do ponto de vista metodológico, Frenken, Oort e Verburg (2007) desenvolveram uma métrica de Variedade Relacionada (VR) e Variedade não Relacionada (VnR) com base no indicador de entropia, utilizando dados de emprego disponíveis na base de dados LISA ${ }^{3}$ desagregados por setor de atividade no nível de cinco dígitos. Neste sentido, a Variedade não Relacionada por região é indicada pela entropia da distribuição das atividades no nível de dois dígitos, ao passo que a Variedade Relacionada é indicada pela soma ponderada da entropia de cada atividade econômica no nível de cinco dígitos dentro de cada grande setor no nível de dois dígitos. Neste trabalho, iremos nos basear esta metodologia para mensurar a VR e a VnR na indústria nos municípios da Região do Médio Paraíba-RJ, conforme detalhado na seção 3.

\section{Complexidade Econômica}

19 A complexidade econômica se propõe explicar o quão complexa e, consequentemente, desenvolvida é uma economia, a partir do tipo de produto que ela produz e exporta. Um produto é sofisticado quando demanda uma grande quantidade de capacidades para ser produzido. Um país diversificado que produz bens mais complexos é uma economia que incorporou conhecimento ao longo do tempo (HAUSMANN; KLINGER, 2007; HIDALGO et al., 2007), sendo, portanto, uma economia desenvolvida e mais complexa (HAUSMANN et al. 2013). No trabalho de Hidalgo et al. (2007) ele utilizou a análise de coocorrência 
para demonstrar como os produtos possuem capacidades semelhantes e, assim, poderiam ser produzidos nos mesmos lugares.

O conceito de complexidade econômica não é novo, e possui outras correntes teóricas ${ }^{4}$. A complexidade, na metodologia de Hidalgo et al. (2007), se refere a uma visão de relatedness ou do grau de relacionamento entre os produtos, que permite entender a especialização dos países. Essa metodologia possibilita calcular as proximidades das capacidades produtivas, a partir da análise da vantagem comparativa revelada ${ }^{5}$ dos produtos. Os pares de produtos que aparecem várias vezes com vantagem competitiva em diferentes países indicam que tais produtos possuem capacidade relacionadas para sua produção. A partir dessa metodologia os autores descobriram que um país complexo possui diversidade produtiva, bem como produzem bens sofisticados. Um produto mais complexo é o que requer um maior conjunto de capacidades para ser produzido, como, por exemplo, aeronaves, química fina, máquinas e equipamentos. Foi criada uma medida para capturar as capacidades disponíveis nos países. Cada capacidade é como um bloco (tipo Lego): países serão capazes de produzir bens sofisticados quando possuírem todas as capacidades necessárias (todos os blocos). Dois pontos são importantes nessa interpretação: a diversidade, que é a quantidade de capacidades (muitos blocos) que um país possui; e a ubiquidade do produto, quando um produto é raro, ou seja, menos ubíquo ele é difícil de ser produzido, assim as capacidades requeridas para determinado produto são difíceis de serem desenvolvidas (blocos raros) em vários lugares. (HAUSMANN et al., 2013; HAUSMANN; HIDALGO, 2010; HIDALGO et al., 2007).

21 Essa metodologia não têm a intenção de demonstrar o processo pelo qual os países acumularam as capacidades, no sentido histórico e qualitativo, mas sim, desenvolver um indicador que sintetize o grau de complexidade dos países e produtos, em determinado período. Segundo os autores, o indicador captura informações sobre um conjunto de capacidades disponíveis em um país. Cabe ressaltar que é uma medida baseada em resultado. Hidalgo et al. (2007) caracterizam essas capacidades de forma "agnóstica", pois segundo eles seria impossível criar um indicador com todas as dimensões possíveis, que poderiam determinar o conjunto exato de insumos, instituições, tecnologias, qualificações, entre outros, de um país. Estes fatores estão relacionados a trajetória dos lugares, assim como explicam os geógrafos econômicos (CONTENT; FRENKEN, 2016).

Os dados sobre complexidade econômica mostraram que o Economic Complexity Index (ECI) é fortemente correlacionado com a renda per capita, o que sugere que países mais complexos são mais ricos. $\mathrm{O}$ indicador pode ser um preditivo do crescimento econômico e da complexidade das exportações futuras, ou seja, é possível verificar produtos potenciais e desenvolvê-los, alavancando assim o crescimento econômico. A partir do cálculo da probabilidade de "coexportação" dos produtos exportados, baseado na coocorrência, os autores descobriram quais produtos são "próximos", ou seja, relacionados. Com base nessa proximidade os autores construíram o espaço de produto, assim como mostra a Figura 1. Essa é uma parte importante na compreensão da estrutura produtiva dos lugares pela ótica da complexidade econômica. 
Figura 1: Metodologia do Espaço de Produtos

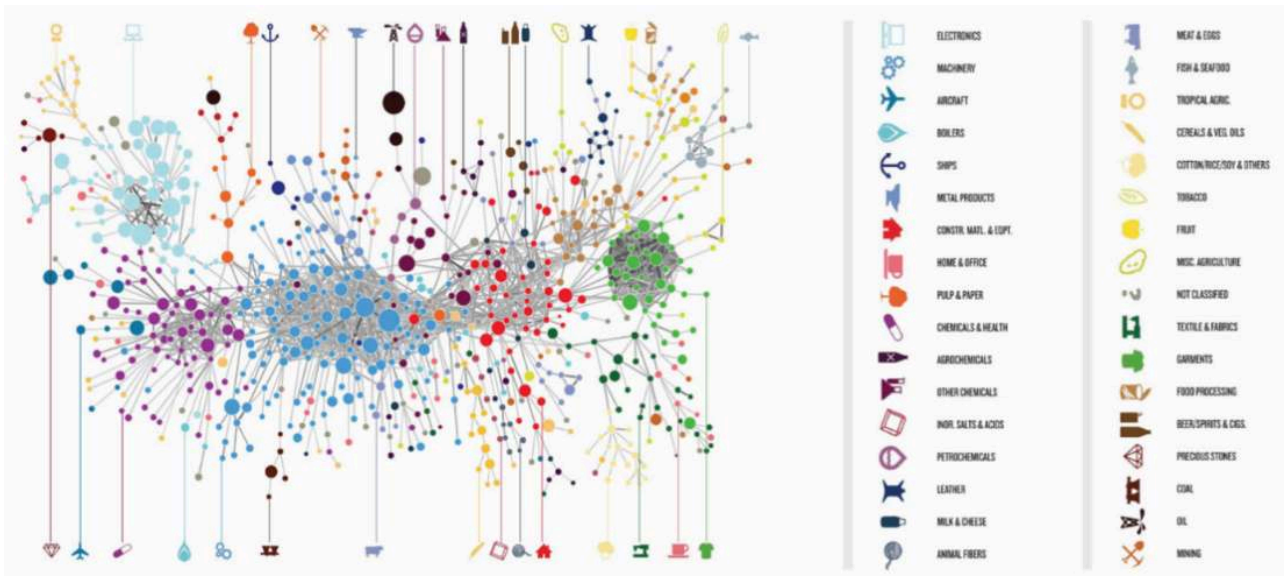

Fonte: HAUSMANN et al., 2013, p. 52

A Figura 1 apresenta a estrutura do espaço de produtos. Esse mapa ajuda a visualizar como os produtos são relacionados em uma rede, onde os 'nós' representam os produtos e seu tamanho é proporcional ao total do bem comercializado internacionalmente. As ligações entre os produtos são feitas por sua proximidade, com base na probabilidade de coexportação de ambos os produtos, e indica que os produtos possuem similaridades nas capacidades requeridas para sua produção. As cores representam os diferentes grupos de produtos. Assim, é possível visualizar e compreender a rede produtivas dos lugares.

Tanto a abordagem de variedade (não)relacionada da Geografia Econômica Evolucionária, como a da Complexidade Econômica de Hausmann et al. (2013), convergem em suas explicações sobre o que o grau de relacionamento e como a diversificação, a partir do conhecimento produtivo existente, pode ser o caminho para o crescimento econômico. Hidalgo et al. (2007) afirmam que relatedness é o próprio espaço de produtos. Os bens pouco complexos possuem poucas ligações com outros bens e os mais complexos possuem muitas ligações. Por isso, o caminho para a complexidade econômica e, consequentemente, para o crescimento econômico, seria produzir os bens mais complexos, que são visualizados no espaço de produtos. Paralelamente, na Geografia Econômica Evolucionária, Frenken, Oort e Verburg (2007) estabeleceram os estudos sobre variedade (não)relacionada, que vão de encontro ao entendimento de diversificação em setores próximos. Posteriormente, Content e Frenken (2016) afirmaram que a metodologia de Hidalgo et al. (2007) é apenas mais uma forma de mensuração da relatedness: "the concept of related variety is also consonant with the concept of product space introduced by Hidalgo et al. (2007)". (CONTENT; FRENKEN, 2016, p. 2099)

No Brasil, já existe um grupo de autores que estão estudando a questão da complexidade econômica em nível nacional e regional (FREITAS et al., 2020; QUEIROZ; ROMERO; FREITAS, 2020; ROMERO et al., 2020; ROMERO; FREITAS, 2018; ROMERO; SILVEIRA, 2019; TORRES, 2019). Esses pesquisadores da Universidade Federal de Minas Gerais (UFMG) e do Centro de Desenvolvimento e Planejamento Regional (Cedeplar) desenvolveram uma plataforma, denominada Data Viva, que fornece uma vasta quantidade de informações, mapas e gráficos desde o nível nacional até o nível municipal. Essa ferramenta será utilizada como recurso metodológico deste trabalho. 


\section{Caracterização socioeconômica da Região Médio Paraíba-RJ}

A região do Médio Paraíba-RJ (RMP-RJ) é composta por doze municípios, situados na porção Sul do estado do Rio de Janeiro. O Mapa 1 apresenta a localização dos municípios e a dimensão populacional de cada município. Como visto, Volta Redonda, Barra Mansa e Resende são os maiores em termos populacionais, revelando correlação direta desse fato com o peso da produção industrial.

Mapa 1: Região Médio Paraíba-RJ, população estimada de 2020 e posição no estado do Rio de Janeiro

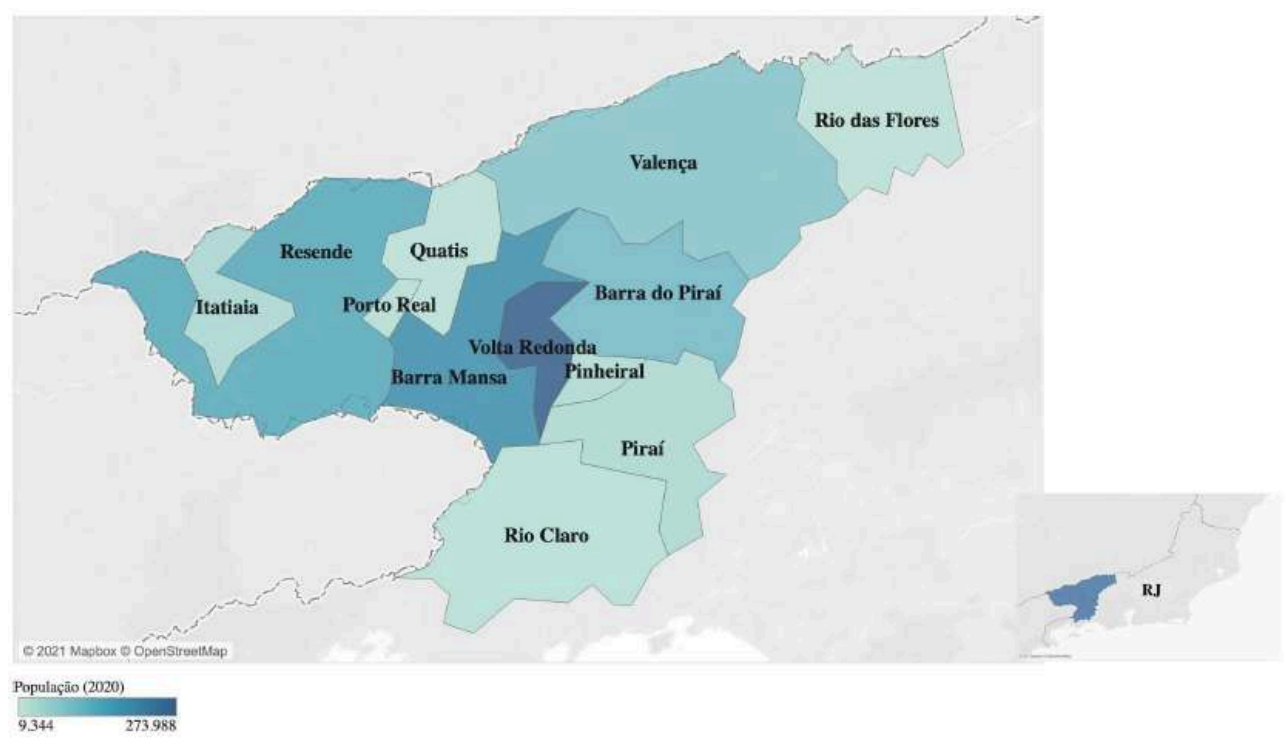

Fonte: Elaboração própria com dados do IBGE.

A RMP-RJ apresenta um histórico de atividade industrial, em especial, na indústria de transformação. A implementação da Companhia Siderúrgica Nacional, em 1941, colocou a região em posição de destaque na industrialização nacional. Por muitos anos a metalurgia foi o principal segmento produtivo da região. Não é por acaso que o município de Volta Redonda é a maior economia da região e possui o maior contingente populacional. Na década de 1990, a região, bem como a economia nacional, vivenciou as transformações advindas com a ideologia liberalizante. Com isso, ocorreu uma profunda transformação da estrutura produtiva da região, a começar pela privatização da CSN em 1992, e a entrada da primeira multinacional, da indústria automotiva Volkswagen Ônibus e Caminhões, no município de Resende. Vasconcellos (2016) discorre sobre o cenário de transição para a região, no qual a participação estatal dá lugar ao setor privado e a produção enxuta da indústria automotiva. A partir disso, começa ocorrer certo compartilhamento da centralidade produtiva na região. Fortalece-se o eixo produtivo regional, que passa a ser composto pela tríade Volta Redonda-Barra Mansa-Resende.

Nos últimos anos, os municípios que possuem as multinacionais automotivas começaram a apresentar maior participação na composição do PIB da região: Resende (20\%), Porto Real (7,5\%) e Itatiaia (11,3\%), para o ano de 2017. Ainda assim, o município de Volta Redonda continua responsável pela maior fatia do PIB regional: apesar de ter 
reduzido sua participação de quase $38 \%$ em 2007, para $29,4 \%$, em 2017, ainda mantém a liderança no que diz respeito ao emprego industrial. No Gráfico 1 é apresentado a evolução do PIB municipal da região, em milhares de reais.

Gráfico 1. PIB da RMP-RJ, por município, 2007-2017

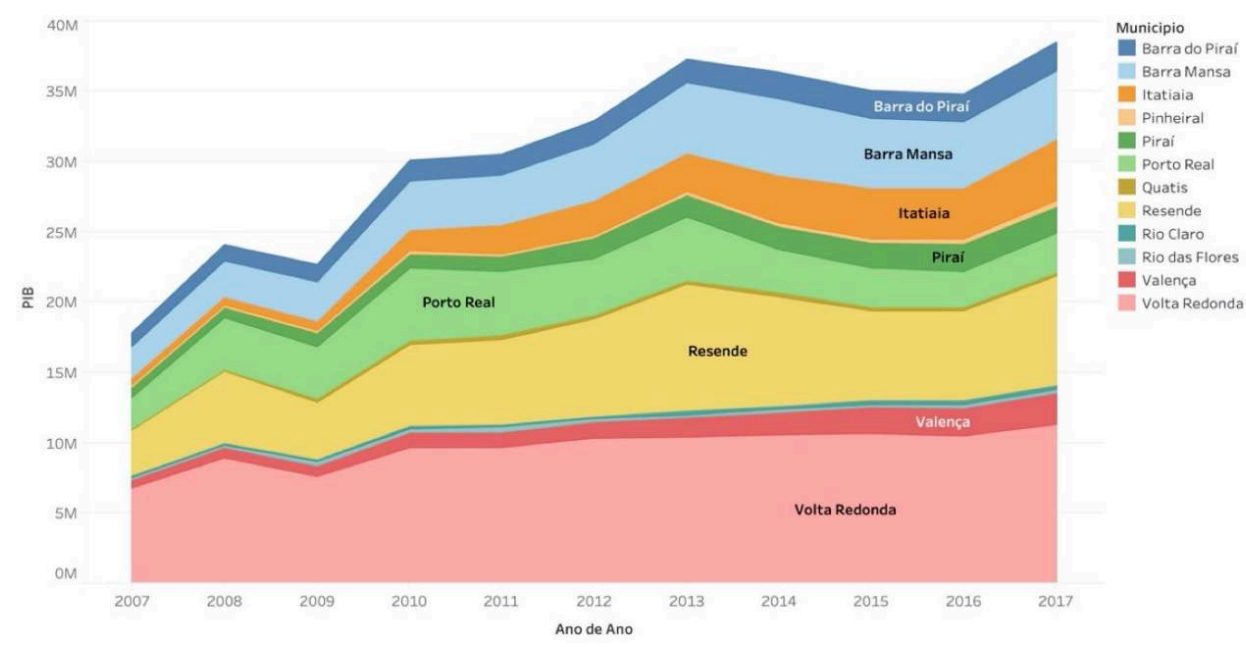

Fonte: Elaboração própria com dados do IBGE (2021)

O Gráfico 1 apresenta o comportamento do crescimento da produção de cada município, ao longo do tempo. Para complementar o entendimento, o Gráfico 2 apresenta a evolução do valor adicionado da indústria nos municípios da região, no mesmo período, tornando mais clara a participação da indústria de cada cidade. Enquanto Volta Redonda apresentou pequena queda, assim como Resende e Barra Mansa, a participação de Itatiaia, Valença e Piraí registraram aumento.

Gráfico 2. Valor Adicionado da indústria na RMP-RJ, por município, 2007-2017

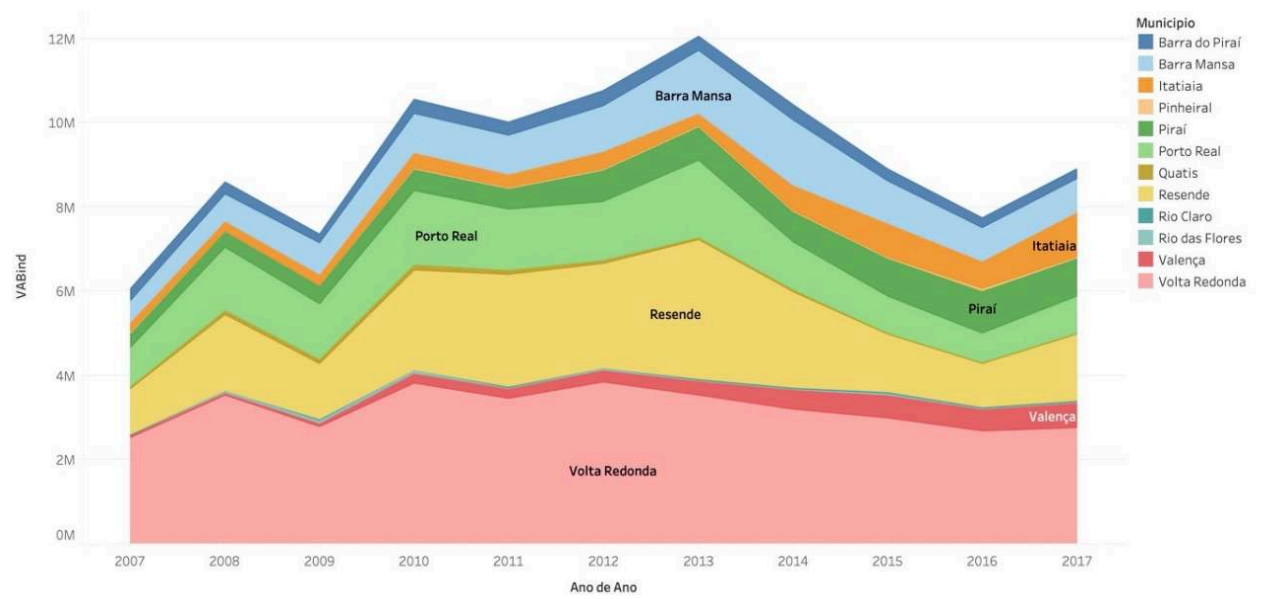

Fonte: Elaboração própria com dados do IBGE.

o Gráfico 2 também deixa explícito o quanto a indústria de transformação sofreu mediante as crises, a queda em 2009 devido à crise internacional de 2008, e a queda em 2016 devido ao aprofundamento da crise econômica brasileira iniciada em 2014. Enquanto isso, no período 2010 a 2013, os dados de crescimento se comportam conforme a economia nacional, que logrou crescimento. $O$ Gráfico 3 fornece um 
panorama do emprego industrial ao longo do tempo. Foram selecionados os municípios que possuem quantidade de emprego relevante para sua economia. Assim, dos doze municípios, apenas oito estão destacados: Volta Redonda, Barra Mansa, Resende, Itatiaia, Porto Real, Barra do Piraí, Piraí e Valença.

Gráfico 3. Evolução do emprego industrial dos principais municípios ${ }^{6}$ e do Médio Paraíba: 2007-2017

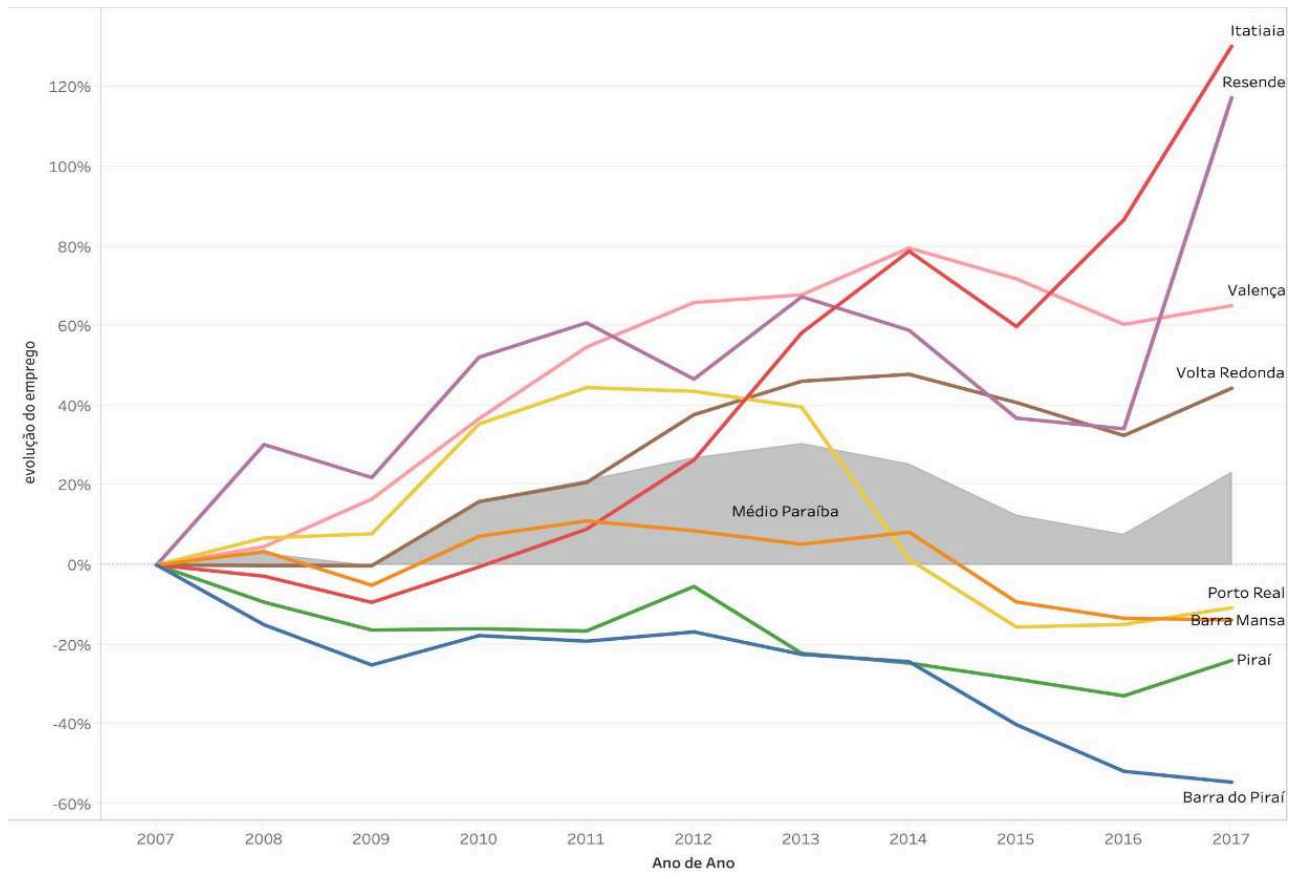

Fonte: Elaboração própria com dados do CAGED.

31 A evolução do emprego industrial revela como alguns municípios vêm perdendo empregos na indústria desde 2007. Mesmo com um cenário de melhora econômica entre 2010 e 2013, o acúmulo de perdas de ocupações de Piraí (-24\%) e Barra do Piraí (-54\%) são acentuados. Enquanto isso, no extremo oposto estão Resende, com ganho de $117 \%$, e Itatiaia, com $130 \%$, ao longo dos onze anos observados. Em Barra do Piraí, o principal segmento, que era o metalúrgico, fechou fábricas e demitiu grande quantidade de trabalhadores, o que influenciou na perda de emprego industrial. Piraí concentra produção nos segmentos de bebida e papel; enquanto o primeiro teve crescimento no número de ocupações devido à expansão de uma fábrica de porte multinacional, o segundo apresentou muitas perdas de emprego, demissões de uma fábrica multinacional - que se recompôs, posteriormente, com a entrada de uma nova fábrica de papel, ocorrida após a coleta dos dados para esse trabalho. Já o município de Itatiaia que concentrava seus empregos na fabricação de pneus, aumentou seus empregos e diversificou para outros segmentos como aparelhos eletrodomésticos e automóveis com achegada da multinacional Jaguar Land Rover e um investimento de R\$ 750 milhões (G1 Auto esporte, 2016). A chegada de duas fábricas da indústria automotiva fez com que o emprego industrial mais do que dobrasse ao longo do tempo observado.

A RMP-RJ possui um eixo econômico, principal, com os três maiores municípios - Volta Redonda, Barra Mansa e Resende - que possuem, historicamente, maior participação no PIB e emprego industrial, assim como as maiores populações. Dessa forma, em termos 
de participação, em Volta Redonda os empregos industriais se mantiveram de acordo com as dinâmicas da CSN, que emprega em torno de 20 mil trabalhadores diretos e terceirizados. Em momentos de crescimento econômico a empresa demanda maior quantidade de mão de obra, enquanto, em momentos de crise, ocorre demissões. Em 2009, devido aos efeitos da crise internacional, um dos dois altos-fornos foi desativado por três meses, enquanto em 2016, a queda da produção foi motivo para desativar um forno para manutenção (ESTADÃO, 2009; G1, 2016). A situação se repetiu em 2020 devido a desativação do Alto-Forno 2 (DIÁRIO DO VALE, 2020). Cada desligamento é acompanhado pela demissão de grande quantidade de trabalhadores.

Em Barra Mansa, houve crescimento de emprego no segmento de alimentos, enquanto outros segmentos se mantiveram estáveis, e foi observada uma queda acentuada na metalurgia, que é tradicional no município. Além de demissões na Votorantim em 2015, a fábrica de cilindros da White Martins foi fechada, no mesmo ano (GI, 2015; FOCO REGIONAL, 2015). Já em Resende ocorreu a entrada de mais uma montadora da indústria automotiva e, por isso, o emprego nos segmentos de automóveis e peça e acessórios para veículos cresceram (G1, 2014). Cabe destacar que o município perdeu empregos em alguns segmentos, como química e defensivos agrícolas.

Gráfico 4: Participação do emprego por atividade econômica no emprego industrial do RMP-RJ, em 2017

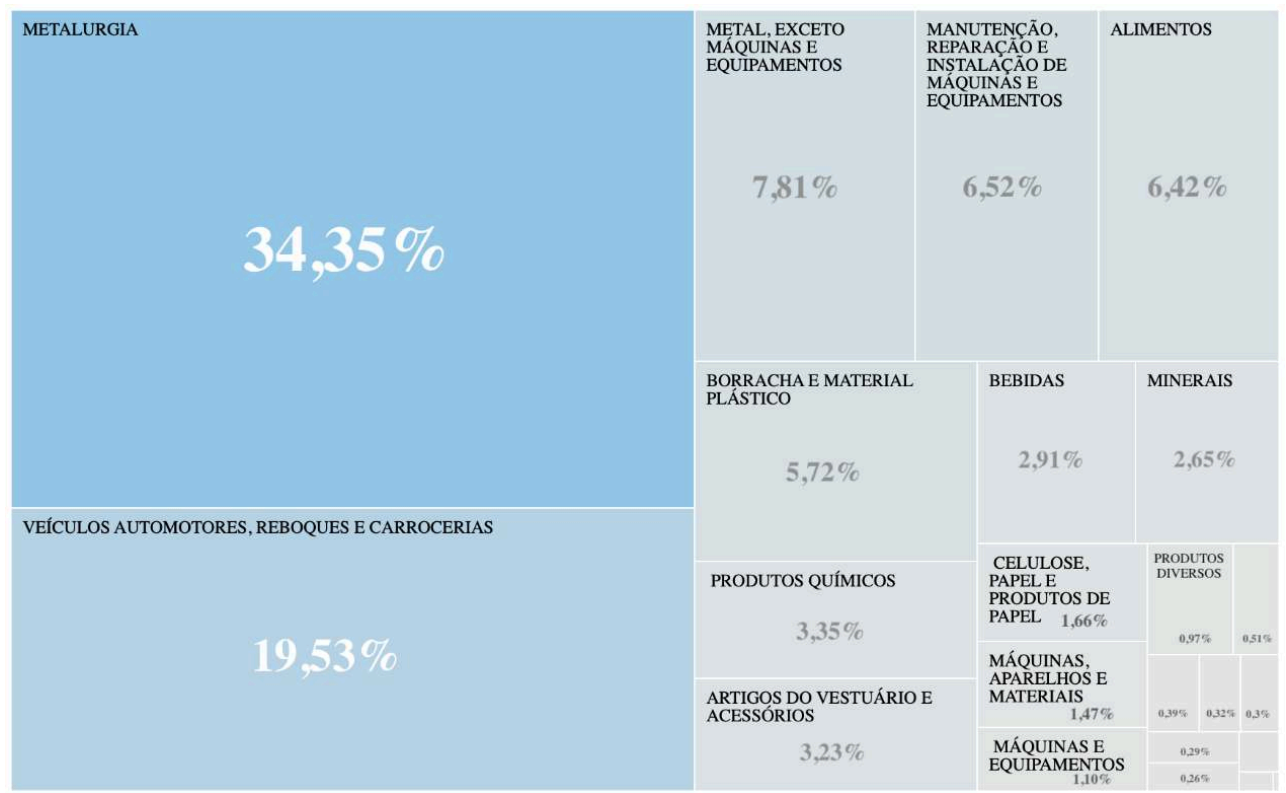

Fonte: Elaboração própria com dados do CAGED (2021)

O Gráfico 4 apresenta as atividades econômicas que compõem a indústria de transformação da região, em 2017. Com o crescimento recente da indústria automotiva, a metalurgia tem diminuído sua participação no total de emprego industrial. Em 2007, a metalurgia empregava $54 \%$ da mão de obra formalmente empregada na indústria, já em 2017 esse percentual diminuiu em razão do crescimento da indústria automotiva. Essa mudança de atividade econômica também impactou o PIB total e o PIB 

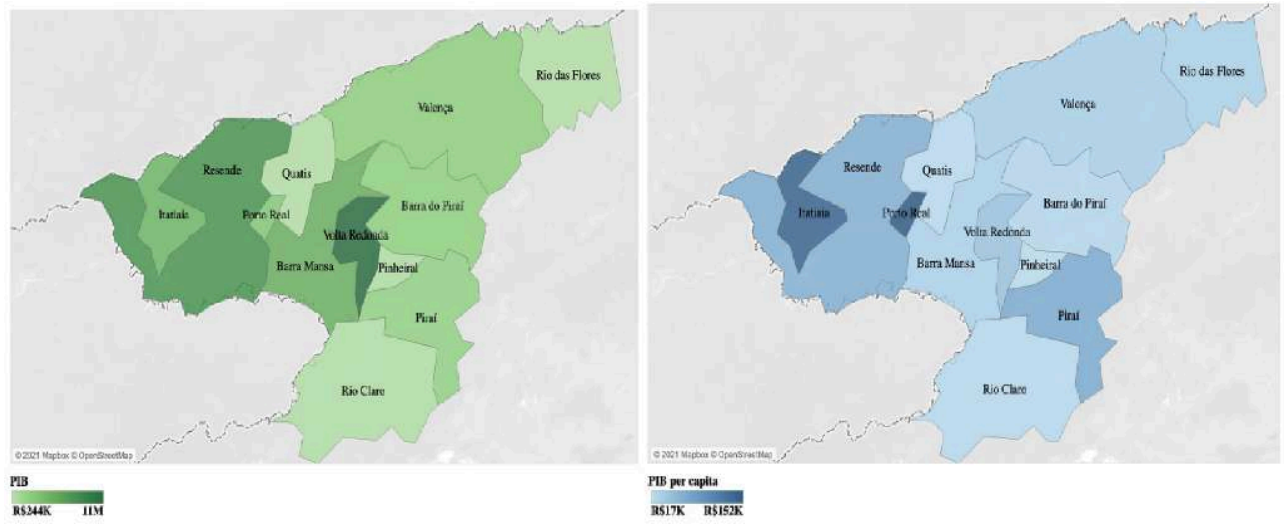

Fonte: Elaboração própria com dados do CEPERJ (2021)

Os municípios da região são bem distintos em relação ao tamanho geográfico, população, PIB e estrutura produtiva. Nesse intuito o Gráfico 5 apresenta tais diferenças: enquanto o município de Volta Redonda possui o maior PIB, seguido por Resende, estes não se destacam no PIB per capita, justamente, pelo tamanho populacional. As indústrias automotivas presentes nos municípios de Porto Real e Itatiaia incrementaram significantemente o PIB per capita, uma vez que estas possuem população muito menor. Uma curiosidade é que tanto Porto Real quanto Itatiaia não possuem universidades em seus territórios, fazendo com que a mão de obra qualificada seja absorvida das cidades vizinhas. A demanda por qualificação pode ser, em certo sentido, verificada na média salarial: nas cidades com multinacionais da indústria automotiva os salários melhores, como pode ser visto no Gráfico 5.

Gráfico 5: Salário Médio da Indústria de transformação dos municípios da RMP-RJ, em 2017

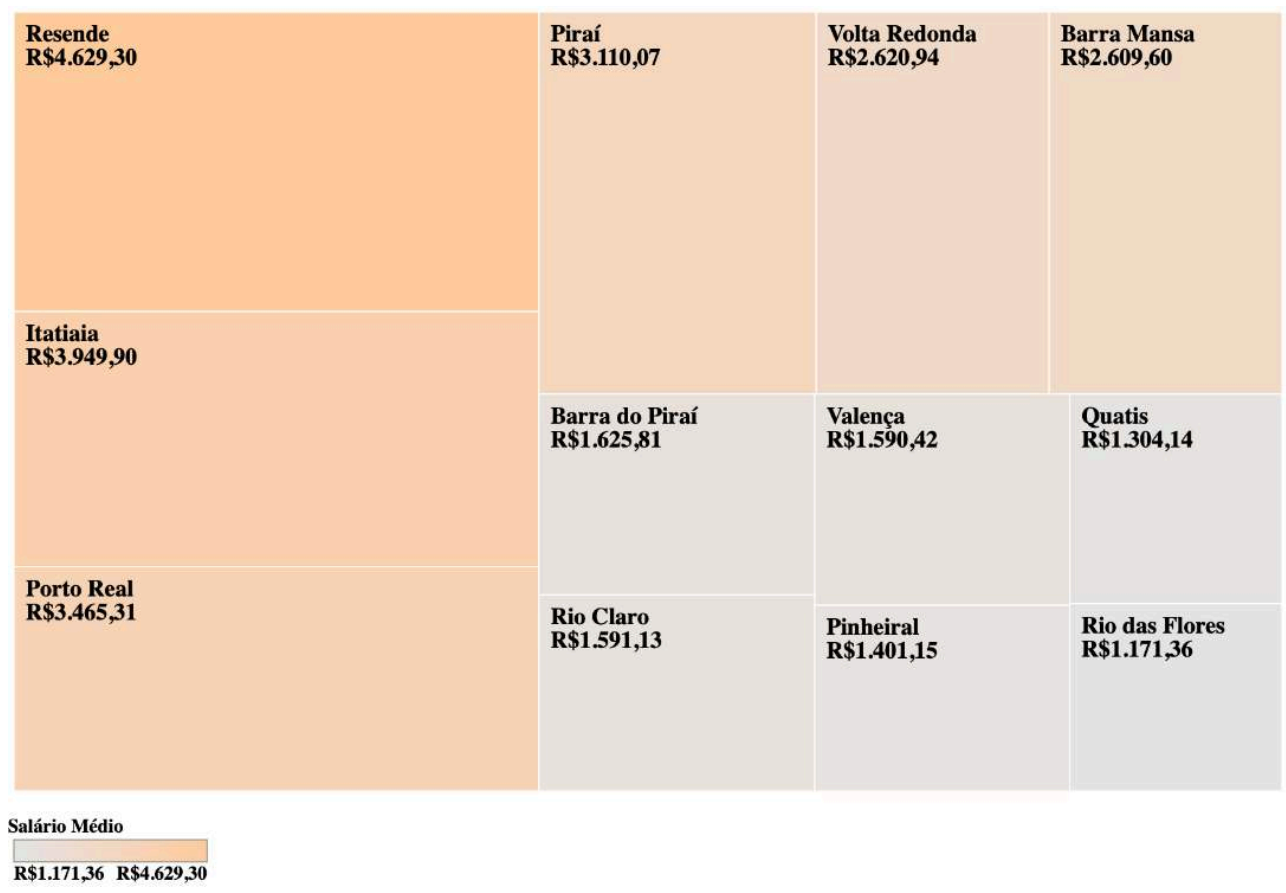

Fonte: Elaboração própria com dados da RAIS (2021) 
36

fins de comparação sobre a dimensão dos valores presente no Gráfico 6, o estado do Rio de Janeiro obteve a maior média salarial entre os estados da feeração, no valor de R\$3.867,84 - enviesado pelo salário médio da indústria do petróleo, que é alto enquanto, São Paulo, em segundo lugar, pagou um salário médio de R\$3.427,04, em 2017. Estes foram os únicos estados acima dos três mil reais, pois a média nacional ficou em $\mathrm{R} \$ 2.637,80$, inclusive próximo da média da região. Dessa forma, nota-se que os municípios de Resende e Itatiaia se destacam com salários acima da média estadual e nacional, seguidos por Porto Real e Piraí, enquanto Barra Mansa e Volta Redonda encontram-se próximos à média nacional.

reflexão interessante emerge desses dados em relação à região: os municípios com pouca indústria pagam salários mais baixos, os municípios com indústrias mais antigas, tradicionais na região, pagam salários médios, e os municípios que abrigam as fábricas mais recentes, como a indústria automotiva, pagam salários maiores. O que não é uma surpresa, dado que a complexidade econômica demonstra que a indústria de transformação possui maior complexidade econômica que a indústria extrativa e agricultura, bem como que indústrias mais complexas e mais sofisticadas são as que possuem mais conexões e demandam mais capacidades produtivas para sua elaboração. Neste sentido, a indústria automotiva é mais complexa do que a metalurgia. A Figura 1 ajuda a dar uma ideia sobre as indústrias mais complexas e que possuem mais conexões, tais como: máquinas e equipamentos, aviões, eletrônicos. Para compreender melhor as dinâmicas produtivas que a região está passando, a seção seguinte detalha a metodologia utilizada para averiguar as mudanças da estrutura produtiva mais a fundo.

\section{Metodologia}

Frenken et al. (2007) propõem dois indicadores capazes de mensurar tanto a VR quanto a VnR utilizando a medida de entropia, que possui, entre outras vantagens, a possibilidade de ser decomposta no nível de dois dígitos. Formalmente, todas as atividades econômicas desagregadas ao nível de cinco dígitos (i) enquadram-se exclusivamente dentro de um grande setor no nível de dois dígitos $(S g)$, onde $g=1,2,3$, ...G. Deste modo, é possível calcular as participações das atividades nos grandes setores ao nível de dois dígitos, $(P g)$, através da soma das participações de cada atividade ao nível de cinco dígitos (pi):

$$
P_{g}=\sum_{i \in S_{g}} p_{i}
$$

Para construir o índice de Variedade Relacionada, os autores calcularam a soma ponderada do indicador de entropia ao nível de cinco dígitos dentro de cada grande setor no nível de dois dígitos. Entropia aqui pode ser entendida como uma medida de desigualdade ou diversidade. Portanto, dado que estamos olhando no interior de um setor específico ao nível de dois dígitos, e como o mesmo é composto pelos seus respectivos subsetores ao nível de cinco dígitos, quanto mais diversos são os subsetores, maior será a entropia. 
Assim, se a Variedade Relacionada é alta, infere-se que os subsetores ao nível de cinco dígitos que compartilham a mesma grande categoria ao nível de dois dígitos se relacionam, pois são mais similares. Por consequência, quanto maior a Variedade Relacionada encontrada nos subsetores ao nível de cinco dígitos dentro da mesma grande categoria ao nível de dois dígitos, maiores são as oportunidades para aprendizado e para transbordamentos de conhecimento. Da mesma forma, quanto maior a variedade, mais a região em questão se beneficiará destes conjuntos de setores diferentes, embora relacionados. A partir do exposto, o índice de Variedade Relacionada (VR) é dado por:

$$
V R=\sum_{g=1}^{G} P_{g} H_{g}
$$

onde:

$$
H_{g}=\sum_{i \in S_{g}} \frac{p_{i}}{p_{g}} \log _{2}\left(\frac{1}{p_{i} / P_{g}}\right)
$$

Desta forma, o índice de Variedade Relacionada é calculado por meio da soma do grau de VR para cada grande setor de atividade ao nível de dois dígitos na respectiva região. Deste modo, quanto maior o indicador de VR, maiores as possibilidades de transbordamento de conhecimento, e, consequentemente, maior potencial de diversificação e de crescimento econômico regional.

Para construir o índice de Variedade não Relacionada, mede-se a entropia da estrutura produtiva regional ao nível de dois dígitos. Este indicador mostra em que medida uma região é caracterizada por diferentes tipos de setores econômicos. Portanto, quanto maior a variedade ao nível de dois dígitos, mais a região é dotada de diferentes setores. Isto deve ser percebido como uma medida do efeito de portfólio da variedade. A entropia no nível de dois dígitos, ou índice Variedade não Relacionada, portanto, é dada por:

$$
V n R=\sum_{g=1}^{G} P_{g} \log _{2}\left(\frac{1}{P_{g}}\right)
$$

Neste sentido, foram utilizados os dados de emprego de todos os setores industriais, ou seja, seção "C" na CNAE 2.0, dentro da divisão 10 a 33, em nível de classe - mesmo os setores que possuíam um único emprego, não foram excluídos - nos anos de 2007, 2012 e 2017, para calcular os indicadores de Variedade Relacionada e Variedade não Relacionada na indústria dos municípios da Região do Médio Paraíba-RJ. 
No tocante ao indicador de complexidade econômica (ECI) usaremos os dados disponibilizados pela plataforma Data Viva, a partir do ranking da complexidade econômica, por municípios, nos anos de 2007, 2012 e 2017. Esse indicador se baseia nos dados do comércio internacional, ou seja, produtos exportados. Os elaboradores deste indicador seguiram a metodologia proposta por Hausmann e Hidalgo (HAUSMANN et al., 2013; HIDALGO et al., 2007; HIDALGO; HAUSMANN, 2009). Para ajustar o indicador ECI da região foram acertados dois detalhes: primeiro, a divisão regional do estado do RJ é diferente na Plataforma Data Viva em relação a classificação oficial estadual. Dessa forma, não existe a dimensão territorial classificada como "Região do Médio Paraíba$\mathrm{RJ}^{\text {", }}$ existe outra dimensão, chamada "Vale do Paraíba Fluminense" que exclui os municípios de Barra do Piraí, Rio das Flores e Valença. Para aproximar um indicador de complexidade econômica para o nível da Região do Médio Paraíba-RJ analisamos duas possibilidades: a primeira foi a média simples da complexidade dos doze municípios das regiões; uma segunda forma foi a verificação da tendência do indicador da microrregião Vale do Paraíba Fluminense. Ambas as formas demonstraram exatamente a mesma tendência do ECI. Um segundo problema verificado foi o município de Valença, que não está presente no ranking de complexidade econômica dos municípios, para o ano de 2017. Para não comprometer a análise foi feita uma aproximação a partir dos indicadores dos anos existentes, conjuntamente, com a análise cuidadosa do Espaço de Produtos do município de Valença.

Por fim, não foram calculados os indicadores de Variedade Relacionada, Variedade não Relacionada e ECI de quatro municípios, devido a quantidade não significante de empregos industriais: Pinheiral, Quatis, Rio Claro e Rio das Flores. Cabe destacar, que os oito municípios restantes compreendem $98 \%$ do emprego industrial da região.

\section{Discussão dos resultados}

Após a caracterização da estrutura da indústria no Médio Paraíba-RJ, seguindo Frenken, Oort e Verburg (2007), foram calculados os indicadores de Variedade Relacionada e Variedade não Relacionada com base nos dados de emprego, como descrito anteriormente. Quanto maior a $\mathrm{VnR}$, mais diversificada setorialmente é a região ou município, ao passo que quanto maior a VR, maior é a diversidade intrasetorial, favorecendo os fluxos de conhecimento e aumentando as possibilidades de diversificação da economia em setores relacionados. 0 Gráfico 6 apresenta a evolução dos indicadores de complexidade econômica, descrito como ECI (Economic Complexity Index), de Variedade Relacionada (VR) e de Variedade não Relacionada (VnR) para o Médio Paraíba-RJ, nos anos de 2007, 2012 e 2017. 
Gráfico 6: Complexidade Econômica (ECI), Variedade Relacionada e Variedade não Relacionada na Região do Médio Paraíba-RJ, 2007, 2012 e 2017

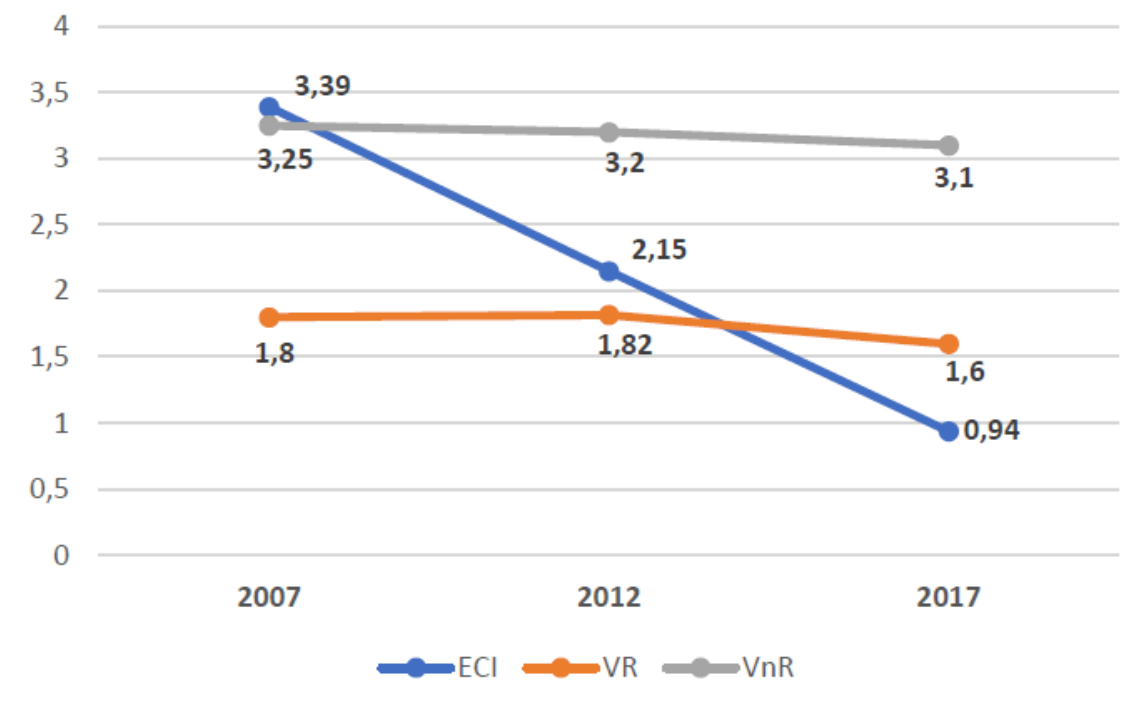

Fonte: Elaboração própria (2021)

Enquanto o indicador de VnR indica o grau de diversificação da estrutura produtiva e o de VR revela o quão diversificado em setores relacionados é a indústria da RMP-RJ, o indicador ECI revela o quão complexa é a região, com base nos produtos exportados. Durante o período, os indicadores de VnR e VR mantém certa estabilidade, apresentando uma pequena queda em 2017. Considerando trabalhos anteriores que calcularam estes índices para o Brasil (Moraes e Luna, 2018) e diferentes regiões do Estado do Rio de Janeiro (Santos, 2020), pode-se inferir que o indicador de VR da região é relativamente elevado, apesar da pequena queda em 2017, ao passo que o indicador de VnR é intermediário. Neste sentido, os dados indicam que a região possui um tecido industrial não muito diversificado, porém com certo grau de variedade relacionada, o que poderia favorecer um processo de diversificação a partir de setores relacionados, baseado em transbordamento de conhecimento e aprendizado interativo. Já a tendência da complexidade apresenta uma queda significativa no período, chegando ao seu menor nível em 2017. Isso indica que a região tem perdido a capacidade de produzir e exportar produtos mais sofisticados.

Cabe destacar que a trajetória dos municípios não é idêntica, em relação aos indicadores (para mais detalhes ver Apêndice 1). Isso significa que enquanto alguns municípios estão ganhando complexidade econômica e diversificação relacionada e não relacionada, outros estão perdendo. A partir dos Mapas apresentados a seguir é possível fazer algumas reflexões sobre a dinâmica dos municípios. Primeiramente, o principal eixo econômico da região - Volta Redonda, Barra Mansa e Resende: enquanto Volta Redonda é o que mais emprega na indústria, também é o que possui os menores indicadores de VR e VnR, i. e., possui a menor diversificação geral e em setores relacionados, o que não surpreende devido ao tamanho da CSN. A tendência do período apresenta perda de complexidade econômica, estabilidade no indicador de VR, e queda expressiva da VnR, tornando ainda mais grave o cenário de forte especialização produtiva da indústria em setores com baixa complexidade. 
Mapas 4, 5 e 6: Índice de Complexidade Econômica dos municípios da RMP-RJ, 2007, 2012 e 2017

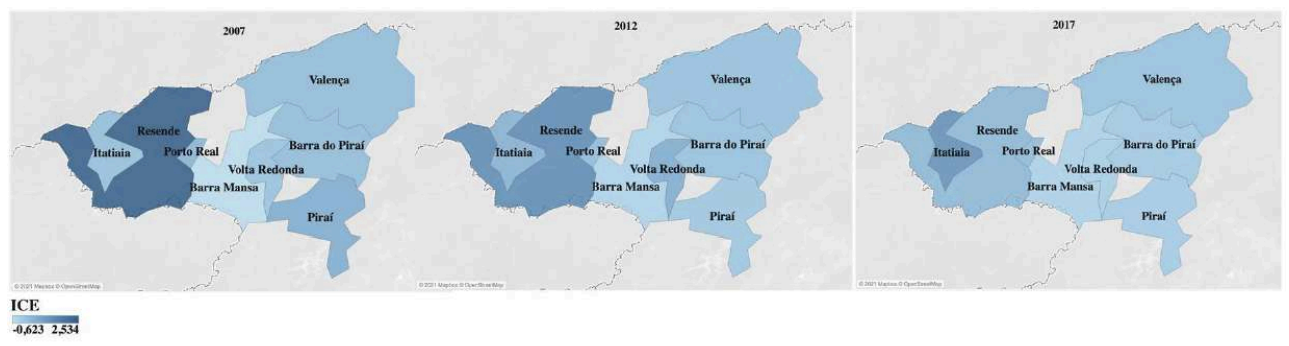

Fonte: Elaboração própria (2021)

Mapas 7, 8 e 9: Índice de Variedade Relacionada dos municípios da RMP-RJ, 2007, 2012 e 2017

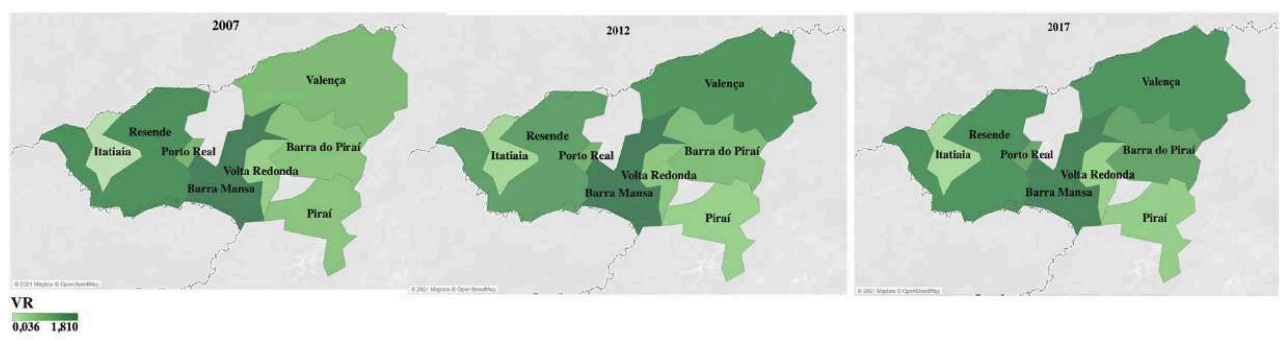

Fonte: Elaboração própria (2021)

Mapas 7, 8 e 9: Índice de Variedade não Relacionada dos municípios da RMP-RJ, 2007, 2012 e 2017

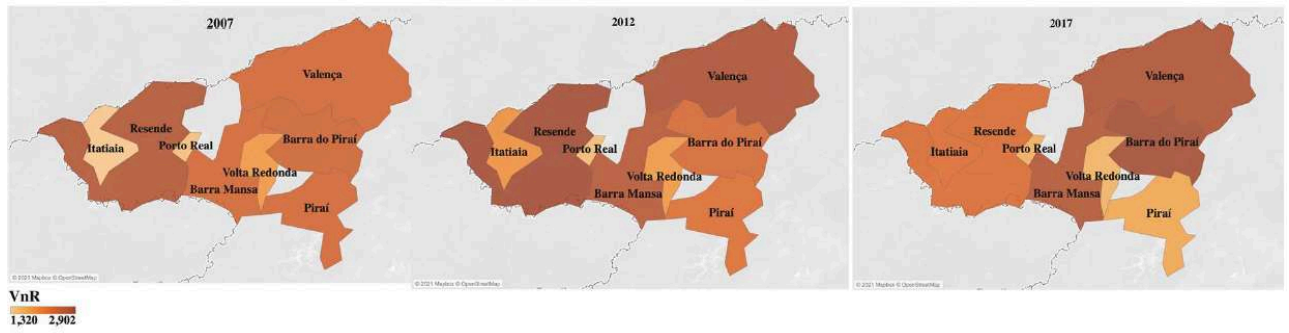

Fonte: Elaboração própria (2021)

O município de Resende foi o que mais perdeu em termos de complexidade econômica, mantendo a VR estável em patamar relativamente elevado comparado aos outros municípios, e tendo queda acentuada da VnR. Isso indica que de um lado houve um processo de concentração industrial em segmentos não complexos, e de outro há oportunidades de alavancar a diversificação em setores relacionados, a partir do estímulo a fluxos de conhecimento, mobilidade de trabalhadores e integração em rede entre empresas de diferentes portes.

Em Barra Mansa, a VR se manteve estável em um patamar relativamente elevado e houve um aumento relevante na VnR, que tem a ver com a diminuição do peso da metalurgia - segmento de tradição. Isso indica que houve um processo de desconcentração industrial e, ao mesmo tempo, abre possibilidades para a diversificação relacionada. Paralelamente, o indicador de complexidade econômica se mantém negativo, o que demonstra a pouca sofisticação produtiva do município. Em linhas gerais, o eixo econômico da região apresenta perdas significativas de 
complexidade econômica, certa estabilidade na VR, porém em patamares distintos, e tendências de concentração industrial em Volta Redonda e Resende e desconcentração em Barra Mansa.

Dentre os municípios "menores", o que mais despontou foi Itatiaia, que teve um forte aumento nos indicadores de VR, porém ainda em patamar muito baixo, e de VnR, que quase dobrou no período, indicando um forte processo de diversificação industrial. Ao mesmo tempo o município ganhou em complexidade econômica com a chegada de novas empresas da indústria automotiva. Barra do Piraí, Valença e Porto Real também registraram ganhos expressivos em VR e VnR, porém sofreram uma perda relevante de complexidade.

53 Em suma, os dados mostram distintas tendências de concentração e desconcentração produtiva da região, assim como diminuição quase generalizada da complexidade econômica. Essas tendências apontam para o enfraquecimento da dinâmica econômica da região, o que pode significar propensão a lock-in tecnológico, maior fragilidade econômica em momentos de crise e menor geração de empregos em segmentos mais sofisticados. No entanto, é importante destacar que essa tendência poderia ser pior, caso não tivesse ocorrido a expansão da indústria automotiva.

\section{Conclusão}

Cada vez mais evidências, teóricas e empíricas, corroboram a ideia de que a indústria de transformação é um elemento chave para o desenvolvimento regional, sobretudo em economias periféricas. No entanto, não adianta apenas ter indústria, pois o tipo de bens que uma economia é capaz de produzir também importa. Em resumo, a construção de capacidades produtivas complexas é crucial neste processo. Os avanços trazidos pela Geografia Econômica Evolucionária e pela chamada "Econofísica" (Gala, 2020), por meio de conceitos como Variedade Relacionada, Variedade não Relacionada e Complexidade, renovaram os debates sobre desenvolvimento regional, robustecendo com evidências empíricas as ideias há tempos aventadas pelos estruturalistas dos anos 1950 e 1960 .

Desta forma, neste artigo recorremos a estes conceitos para realizar uma abordagem original acerca das mudanças da estrutura produtiva da Região Médio Paraíba do Estado do Rio de Janeiro, buscando identificar as tendências de sua estrutura produtiva, bem como as ameaças e oportunidades para o seu desenvolvimento em longo prazo. A combinação entre Complexidade e Variedade (não)Relacionada pode trazer pistas importantes para pesar as possibilidades de renovação ou criação de novas trajetórias de desenvolvimento.

Analisando um período de tempo marcado tanto por bonança econômica (2007 a 2014) quanto por uma crise severa (2014 a 2017), foi possível observar tendências preocupantes da economia regional: seu principal eixo econômico - Resende, Barra Mansa e Volta Redonda - registrou uma tendência de concentração econômica e perda de diversidade intrasetorial, i. e., queda ou baixo nível de VR e VnR, associada a perda de complexidade, o que dificulta processos de inovação e transbordamento de conhecimento, indica um processo de desadensamento produtivo e especialização em setores pouco complexos. Os demais municípios, à exceção de Itatiaia, lograram diversificar suas estruturas produtivas intra e intersetorialmente, porém perderam complexidade produtiva, o que demonstra um processo mais amplo de enfraquecimento dos elos e das capacidades produtivas. Somente o município de 
Itatiaia se destacou, contudo, sua participação na economia regional ainda é bastante diminuta.

Esta abordagem, inédita para a região, joga luz sobre novos aspectos e demonstra, empiricamente, os perigos oriundos da especialização em poucos setores e da forte dependência a um conjunto de empresas multinacionais, que não possuem conexões sociais profundas com o território. Neste contexto, além do risco de aprisionamento tecnológico, choques e crises econômicas podem trazer efeitos bastante perversos para a região, como desemprego pelo fechamento de fábricas e perda de mão de obra qualificada.

Ao mesmo tempo que acende um sinal de alerta, o uso da abordagem proposta pela Geografia Econômica Evolucionária e pela Economia da Complexidade também permite identificar oportunidades para a renovação da trajetória de desenvolvimento regional a partir das capacidades e setores existentes. Este artigo representa um primeiro esforço neste sentido, porém, não obstante a carência de dados, é possível em trabalhos futuros se aprofundar na análise da estrutura regional para verificar os setores potencias e mais complexos, relacionados aos existentes, através dos quais o processo de diversificação regional poderia avançar.

Por fim, cabe ressaltar que sem um diagnóstico bem feito não é possível formular e executar políticas públicas adequadas, que, por sua vez, são cruciais para guiar o processo de desenvolvimento regional. Este artigo, portanto, além de trazer uma contribuição teórica - combinação de abordagens - e empírica - aplicação ao caso fluminense -, também contribui de forma prática, ao oferecer um panorama mais aprofundado das mudanças na estrutura produtiva regional que pode servir aos gestores públicos e tomadores de decisão.

Apêndice 1

Tabela: Evolução do Indicador de Complexidade Econômica (ECI) Variedade Relacionada (VR) e Variedade não Relacionada, por municípios, 2007, 2012 e 2017

\begin{tabular}{|l|r|r|r|r|r|r|r|r|r|}
\hline \multirow{2}{*}{\begin{tabular}{l} 
Municípios \\
\cline { 2 - 11 }
\end{tabular}} & \multicolumn{9}{|c|}{ Indicadores } \\
\cline { 2 - 11 } & $\mathbf{2 0 0 7}$ & $\mathbf{2 0 1 2}$ & $\mathbf{2 0 1 7}$ & $\mathbf{2 0 0 7}$ & $\mathbf{2 0 1 2}$ & $\mathbf{2 0 1 7}$ & $\mathbf{2 0 0 7}$ & $\mathbf{2 0 1 2}$ & $\mathbf{2 0 1 7}$ \\
\hline $\begin{array}{l}\text { Barra do } \\
\text { Pirai }\end{array}$ & 0,193 & 0,066 & -120 & 0,601 & 0,696 & 1,153 & 2,459 & 2,373 & 2,866 \\
\hline $\begin{array}{l}\text { Barra } \\
\text { Mansa }\end{array}$ & 0,623 & 0,378 & 0,342 & 1,790 & 1,810 & 1,686 & 2,398 & 2,696 & 2,741 \\
\hline Itatiaia & 0,119 & 0,413 & 1,219 & 0,036 & 0,237 & 0,183 & 1,320 & 1,906 & 2,293 \\
\hline Pirai & 0,569 & 0,076 & 0,167 & 0,583 & 0,388 & 0,436 & 2,408 & 2,288 & 1,688 \\
\hline Porto Real & 0,357 & 0,195 & 0,202 & 0,805 & 0,866 & 1,080 & 1,419 & 1,481 & 1,606 \\
\hline Resende & 2,534 & 1,380 & 0,280 & 1,518 & 1,242 & 1,469 & 2,736 & 2,902 & 2,331 \\
\hline Valença & 0,202 & 0,086 & 0,060 & 0,752 & 1,408 & 1,426 & 2,417 & 2,809 & 2,777 \\
\hline $\begin{array}{l}\text { Volta } \\
\text { Redonda }\end{array}$ & 0,037 & 0,550 & 0,253 & 0,397 & 0,542 & 0,367 & 1,841 & 1,829 & 1,564 \\
\hline
\end{tabular}




\section{BIBLIOGRAFIA}

ASHEIM, Bjørn T.; BOSCHMA, Ron; COOKE, Philip. Constructing regional advantage: Platform policies based on related variety and differentiated knowledge bases. Regional Studies, v. 45, n. 7, p. 893-904, 2011.

BATISTA, Ivone Lopes. Redes produtivas e novas territorialidades no sul Fluminense. Anuário do Instituto de Geociências, Rio de Janeiro, v. 29, n. 2, p. 233-234, 2006.

BOSCHMA, Ron; IAMMARINO, Simona. Related variety, trade linkages, and regional growth in Italy. Economic geography, v. 85, n. 3, p. 289-311, 2009.

BOSCHMA, Ron. Relatedness as driver of regional diversification: a research agenda. Regional Studies, v. 51, n. 3, p. 351-364, 2017.

BRASIL. MINISTÉRIO do Trabalho e Emprego - MTE. Relação Anual de Informações Sociais - RAIS.

BRESCHI, Stefano; LISSONI, Francesco; MALERBA, Franco. Knowledge-relatedness in firm technological diversification. Research policy, v. 32, n. 1, p. 69-87, 2003.

CAGED. Cadastro Geral de empregados e desempregados do Ministério do Trabalho e Emprego. Base de dados on line. Disponível em: https://www.caged.gov.br/index.html. Acesso em: 29/08/2019.

CASTALDI, Carolina; FRENKEN, Koen; LOS, Bart. Related variety, unrelated variety and technological breakthroughs: an analysis of US state-level patenting. Regional studies, v. 49, n. 5, p. 767-781, 2015.

CONTENT, Jeroen; FRENKEN, Koen. Related variety and economic development: a literature review. European Planning Studies, v. 24, n. 12, 2016.

DABOÍN, Carlos; ESCOBARI, Marcela; HERNÁNDEZ, Gabriel; MORALES-ARILLA, José. Economic Complexity and Technological Relatedness: Findings for American Cities. n. 2014, p. 1-34, 2019.

Data Viva: disponível em < http://dataviva.info> acesso em 18 de maio de 2020

ESTADÃO. CSN pode dmitir mais de 900 em Volta Redonda, diz sindicato. Disponível em <https:// economia.estadao.com.br/noticias/geral,csn-pode-demitir-mais-900-em-volta-redonda-dizsindicato,311286> Acesso em 03/05/2020

DIÁRIO DO VALE. CSN começa a abafar AF-2 e prepara pacote de demissões na Usina. Disponível em <https://diariodovale.com.br/tempo-real/csn-comeca-a-abafar-af-2-e-prepara-pacote-dedemissoes-na-usina/> Acesso em 20/06/2020

FIRJAN. Mercado de Trabalho 2014 - Região Sul Fluminense Disponível em < https:// www.firjan.com.br/lumis/portal/file/fileDownload.jsp?

fileId=2C908A8F4EB14A4C014EB6A12DDF4937\&inline=1> Acesso em 20/06/2020

FREITAS, Elton; SILVEIRA, Fabricio; CIMINI, Fernanda; ROMERO, João Prates. Complexidade econômica e especialização inteligente: uma proposta de política de diversificação para o desenvolvimento de Minas Gerais. p. 1-25, 2020.

FRENKEN, Koen; OORT, Frank Van; VERBURG, Thijs Nicolaas. Related variety, unrelated variety and regional economic growth. Regional Studies, v. 12, p. 1537-1546, 2007.

FRENKEN, Koen. Innovation, Evolution and Complexity Theory. Edward Elgar, Cheltenham, UK, 2006. 
FOCO REGIONAL. Acordo barra 140 demissões na Votorantim em Barra Mansa. Disnponível em < https://focoregional.com.br/Noticia/acordo-barra-140-demissoes-na-votorantim-em-b> Acesso em $15 / 09 / 2020$

GLAESER, Edward; KALAL, Hedid; SCHEINKINAN, Jose; SHLEIFER, Andrei. Growth in cities. Journal of political economy, v. 100, n. 6, p. 1126-1152, 1992.

G1. Nissan inaugura nova fábrica em Resende, RJ. Disponível em em < http://g1.globo.com/rj/suldo-rio-costa-verde/noticia/2014/04/nissan-inaugura-nova-fabrica-em-resende-rj.html> Acesso em $10 / 02 / 2020$

G1. Fábrica fecha as portas e demite 120 trabalhadores em Barra Mansa, RJ. Disponível em < http://g1.globo.com/rj/sul-do-rio-costa-verde/noticia/2015/11/fabrica-fecha-portas-edemite-120-trabalhadores-em-barra-mansa-rj.html> Acesso em 10/09/2020

G1. Após 700 demissões, CSN interrompe cortes em Volta Redonda, diz sindicato. Disponível em < http://g1.globo.com/rj/sul-do-rio-costa-verde/noticia/2016/01/apos-700-demissoes-csninterrompe-cortes-em-volta-redonda-diz-sindicato.html> Acesso em 05/02/2020

G1 AUTO ESPORTE. Jaguar Land Rover inaugura fábrica em Itatiaia (RJ) para produzir Evoque. Disponível em < http://g1.globo.com/carros/noticia/2016/06/jaguar-land-rover-inaugurafabrica-em-itatiaia-rj-para-produzir-evoque.html> Acesso em 05/10/2020.

GALA, Paulo. Econofísica: uma ideia cujo tempo chegou. Blog do Paulo Gala: Economia \& Finanças, publicado em 19 de abril de 2020. Disponível em: < https://www.paulogala.com.br/econofisicauma-ideia-cujo-tempo-chegou/> Acesso em 09/07/2021

HAUSMANN, Ricardo; HIDALGO, César; BUSTOS, Sebastián; COSCIA, Michele; SIMOES, Alexander; YILDIRIM, Muhammed A. The atlas of Economic Complexity: Mapping paths to prosperith.. MIT Press, 2013.

HAUSMANN, Ricardo.; HIDALGO, César. Country diversification, product ubiquity, and economic divergence. CID Working Papers, v. 201, 2010.

HAUSMANN, Ricardo; KLINGER, Bailey. The Structure of the Product Space and the Evolution of Comparative Advantage. CID working paper, Harvard University, Cambridge, n. No. 146, p. 37, 2007.

HIDALGO, César; KLINGER, Bailey; Alberto Barabasi; HAUSMANN, Ricardo. The Product Space Conditions the Development of Nations. Scientific Detectors Workshop, n. 1, p. 1-13, 2007.

HIDALGO, César; HAUSMANN, Ricardo. The building blocks of economic complexity. Proceedings of the National Academy of Sciences of the United States of America, v. 106, n. 26, p. 10570-10575, 2009.

IBGE - INSTITUTO BRASILEIRO DE GEOGRAFIA E ESTATÍSTICA. IBGE cidades, Indicadores Municipais Disponível em: < https://cidades.ibge.gov.br> Acesso em 20/08/2019 IBGE Comissão Nacional de Classificação - Concla. Disponível em < https:// cnae.ibge.gov.br> Acesso em 20/09/2019 JACOBS, Jane. The Economy of Cities. New York: Penguin Books, 1969.

MAMELI, Francesca; IAMMARINO, Simona; BOSCHMA, Ron. Regional variety and employment growth in Italian labour market areas: services versus manufacturing industries. CIMR Research Working Paper Series, n. 4, p. 1-23, 2012.

MARX, Karl. O capital-Livro 3: Crítica da economia política. O processo de circulação do capital. Boitempo Editorial, 2017 [1872]. 
MONTEIRO, Cristiano Fonseca; DA COSTA LIMA, Raphael Jonathas. Entidades empresariais e desenvolvimento no Sul Fluminense: governança, estratégia e estrutura. Revista Pós Ciências Sociais, v. 12, n. 24, p. 101-116, 2015.

OREIRO, José Luis; FEIJO, Carmem A.; Desindustrialização: conceituação, causas, efeitos e o caso brasileiro. Revista de Economia Política, vol. 30, no 2 (118), pp. 219-232, abril-junho/2010.

PÉREZ, Carlota. Dinamismo tecnológico e inclusión social en América Latina: una estrategia de desarrollo productivo basada en los recursos naturales. Revista Cepal 100, abril 2010, 123-145 p. QUEIROZ, Arthur; ROMERO, João Prates; FREITAS, Elton. Estratégia de Diversificação Produtiva : Uma Proposta para Aumentar a Complexidade Econômica e o Emprego dos Estados Brasileiros Estratégia de Diversificação Produtiva : Uma Proposta para Aumentar a Complexidade Econômica e o Emprego dos Estados Brasileir. 2020.

RAMALHO, José Ricardo; SANTOS, Rodrigo Salles Pereira dos; LIMA, Raphael Jonathas da Costa. Estratégias de desenvolvimento industrial e dinâmicas territoriais de contestação social e confronto político. Sociologia \& Antropologia, v. 3, n. 5, p. 175-200, 2013.

RODRIGUES, Iram Jácome; RAMALHO, José Ricardo Garcia Pereira. Trabalho e sindicato em antigos e novos territórios produtivos: comparações entre o $\mathrm{ABC}$ paulista e o sul fluminense. Annablume, 2007.

ROMERO, João Prates; CIMINI, Fernanda; SILVEIRA, Fabrício; JAYME, Frederico; FREITAS, Elton; ROCHA, Gustavo de Britto. IDENTIFICAÇÃO DE SETORES E ATIVIDADES PARA O DESENVOLVIMENTO DE BELO HORZIONTE : COMPLEXIDADE ECONÔMICA APLICADA. Belo Horizonte: CEDEPLAR, 2020.

ROMERO, João Prates; FREITAS, Elton. Setores promissores para o desenvolvimento do Brasil: complexidade e espaço do produto como instrumentos de política. In: ANDRADE, M. V.; ALBUQUERQUE, E. DA M. (Eds.). . Alternativas para uma crise de múltiplas dimensões. Belo Horizonte: CEDEPLAR, 2018. p. 358-373.

ROMERO, João Prates; SILVEIRA, Fabrício. Mudança estrutural e complexidade econômica : identificando setores promissores para o desenvolvimento dos estados brasileiros. In: LEITE, M. V. C. (Ed.). . Alternativas para o desenvolvimento brasileiro: Novos horizontes para a mudança estrutural com igualdade. [s.l.] CEPAL, 2019. p. 137-160.

RICUPERO, Rubens. Desindustrialização precoce: futuro ou presente do Brasil?. 2014.

SMITH, Adam. A riqueza das nações investigação sobre sua natureza e suas causas. São Paulo: Abril Cultural, 1983 [1776].

TORRES, Guilherme Sganserla. Complexidade econômica : uma proposta metodológica para identificação de produtos estratégicos identificação de produtos estratégicos. [s.l.] UFMG, 2019.

VASCONCELLOS, Bianca Louzada Xavier. Desenvolvimento regional e estrutura produtiva: um estudo sobre a região do Médio Paraíba (RJ). Orientador: Robson Dias da Silva. 2016. 186 f. Dissertação (Mestrado Desenvolvimento Territorial e Políticas Públicas) - Universidade Federal Rural do Rio de Janeiro, Seropédica, 2016.

WIXE, Sofia; ANDERSSON, Martin. Which types of relatedness matter in regional growth? Industry, occupation and education. Regional Studies, 2017.

Fonte: Elaboração própria (2021) 


\section{NOTAS}

1. Ver RODRIGUES e RAMALHO (2007); BATISTA (2006); RAMALHO, SANTO e LIMA (2013); MONTEIRO e LIMA (2015); VASCONCELLOS (2016).

2. No sentido quantitativo, pois a corrente que trata sobre a industrialização, desenvolvimento técnico e desenvolvimento de setores com maior valor agregado, remota aos estudos da CEPAL, desde 1950.

3. Longitudinal integrated database for health insurance and labour market studies. (https:// www.scb.se/en/services/guidance-for-researchers-and-universities/vilka-mikrodata-finns/ longitudinella-register/longitudinal-integrated-database-for-health-insurance-and-labourmarket-studies-lisa/).

4. ANDERSON et al. (1988) sobre a economia como sistemas complexos; ARTHUR (1999), complexidade a partir de padrões econômicos fora do equilíbrio e que evoluem, que compreende o grupo de pesquisa do Santa Fe Institute, com longa tradição no debate sobre complexidade econômica; e autores da economia evolucionária, como Frenken, Oort e Verburg (2007) e Martin \& Sunley (2007).

5. Ver Balassa (1965)

6. Nesse gráfico a análise se concentra nos municípios que possuem maior participação no PIB e VAB industrial da região: Volta Redonda, Barra Mansa, Resende, Barra do Piraí, Piraí, Itatiaia, Valença e Porto Real.

7. Essa divisão foi escolhida pelas características industriais compartilhadas, proximidade geográfica, mão de obra compartilhada etc. entre os municípios.

\section{RESUMOS}

Apesar da crescente importância do setor de serviços, a indústria manufatureira ainda mantém grande relevância para o desenvolvimento regional. Neste contexto, a Região do Médio ParaíbaRJ (RMP-RJ), que possui uma larga trajetória e cultura industrial, é um exemplo das mudanças estruturas que ocorreram na economia brasileira desde a década de 1990, com destaque para as privatizações e entrada de multinacionais. Recentemente, contribuições trazidas pelas abordagens da Geografia Econômica Evolucionária e da Complexidade Econômica trouxeram lastro empírico sobre diversificação produtiva. Este artigo, portanto, tem como objetivo analisar as mudanças recentes da estrutura produtiva na RMP-RJ sob a ótica da Variedade (não)Relacionada (VR e VnR) e da Complexidade Econômica. Para tanto, utilizamos a metodologia desenvolvida pelos autores seminais desta abordagem para calcular os indicadores de VR e VnR, bem como o índice de Complexidade Econômica, para os principais municípios da região nos anos de 2007, 2012 e 2017, a fim de analisar a evolução de sua estrutura produtiva. Os resultados apontaram uma tendência geral de concentração econômica, perda de densidade produtiva, diminuição da diversidade intersetorial e queda da complexidade econômica, apontando para a necessidade de uma agenda de desenvolvimento baseada na geração de conhecimento e construção de capacidades produtivas capaz de superar tais desafios e servir de base para uma nova trajetória de desenvolvimento.

Despite of the increasing share of service in global economy, manufacturing stills playing a pivotal role for regional development. The Rio de Janeiro's State region known as "Médio 
Paraíba" has a long industrial history and has been pinpointed as an example of the structural changes that have taken place in the Brazilian economy since the 1990s, many of those rooted on privatizations and foreign investment inflow. Recently, the Evolutionary Economic Geography and Economic Complexity have contributed for the deepen understanding of manufacturing shifts worldwide by providing both theoretical and empirical about productive diversification. This article aims to analyze the recent changes in the productive structure in the "Médio Paraíba" by using both the perspective of (un)Related Variety (VR and VnR) and Economic Complexity. Therefore, it used the methodology developed by the seminal authors of this approach to calculate the VR and VnR indicators, as well as the Economic Complexity index, for the main municipalities in the region in the years 2007, 2012 and 2017 to analyze the evolution of its productive structure. The results showed a trend of economic concentration, lowering productive density, decrease in intersectoral diversity and a drop in economic complexity. The outputs point out the need for a development agenda based on the generation of knowledge and construction of productive capacities capable of overcoming such challenges and serve as the basis for a new development trajectory.

A pesar de la creciente participación del servicio em economía mundial, la industria manufacturera sigue con gran relevancia para el desarrollo regional. La Región "Médio ParaíbaRJ" tiene una larga historia y cultura industrial, es un ejemplo de los cambios estructurales que se han producido en la economía brasileña desde la década de 1990, muchos de ellos arraigados en las privatizaciones y la entrada de multinacionales. Recientemente, las contribuciones de la Geografía Económica Evolutiva y la Complejidad han contribuido a profundizar la comprensión de los cambios en la manufactura en todo el mundo al ofertar información teórica y empírica sobre la diversificación productiva. Este artículo tiene como objetivo analizar los cambios recientes en la estructura productiva del "Médio Paraíba" desde la perspectiva de la Variedad (no)Relacionada (VR y VnR) y la Complejidad Económica. Por ello, utilizó la metodología elaborada por los autores seminales de este enfoque para calcular los indicadores de VR y VnR, así como el índice de Complejidad Económica, para los principales municipios de la región en los años 2007, 2012 y 2017 para analizar la evolución de su estructura productiva. Los resultados mostraron una tendencia de concentración económica, disminución de la densidad productiva, disminución de la diversidad intersectorial y disminución de la complejidad económica. Los productos señalan la necesidad de una agenda de desarrollo basada en la generación de conocimiento y construcción de capacidades productivas capaces de superar tales desafíos y que sirvan de base para una nueva trayectoria de desarrollo..

Malgré la part croissante des services dans l'économie mondiale, la fabrication joue toujours un rôle central pour le développement régional. La région de l'État de Rio de Janeiro connue sous le nom de "Médio Paraíba" a une longue histoire industrielle et a été identifiée comme un exemple des changements structurels qui ont eu lieu dans l'économie brésilienne depuis les années 1990, dont beaucoup ont pour origine les privatisations et l'afflux d'investissements étrangers. . Récemment, la géographie économique évolutive et la complexité économique ont contribué à approfondir la compréhension des changements manufacturiers dans le monde en fournissant à la fois théorique et empirique sur la diversification productive. Cet article vise à analyser les changements récents de la structure productive dans le "Médio Paraíba" en utilisant à la fois la perspective de la variété (non)reliée (VR et VnR) et de la complexité économique. Par conséquent, il a utilisé la méthodologie développée par les auteurs fondateurs de cette approche pour calculer les indicateurs VR et VnR, ainsi que l'indice de complexité économique, pour les principales communes de la région dans les années 2007, 2012 et 2017 pour analyser l'évolution de la sa structure productive. Les résultats ont montré une tendance à la concentration économique, à la baisse de la densité productive, à la diminution de la diversité intersectorielle et à une baisse de la complexité économique. Les résultats soulignent la nécessité d'un programme 
de développement basé sur la génération de connaissances et la construction de capacités productives capables de surmonter ces défis et de servir de base à une nouvelle trajectoire de développement.

\section{ÍNDICE}

Mots-clés: Médio Paraíba-RJ ; Variété (non) apparentée ; Complexité économique ; Fabrication; Développement régional

Keywords: Médio Paraíba-RJ; (Un)Related Variety; Economic complexity; Manufacture; Regional development

Palabras claves: Medio Paraíba-RJ; Variedad (no) relacionada; Complejidad económica; Industria; Desarrollo regional

Palavras-chave: Médio Paraíba-RJ; Variedade (Não)relacionada; Complexidade Econômica; Indústria; Desenvolvimento Regional

\section{AUTORES}

\section{BIANCA LOUZADA XAVIER VASCONCELLOS}

Universidade Federal do Rio de Janeiro (UFRJ). Doutoranda no Programa de Pós-Graduação em Política Pública, Estratégia e Desenvolvimento (PPED/UFRJ).E-mail: bianca.ufrrj@gmail.com

\section{GUILHERME DE OLIVEIRA SANTOS}

Universidade Federal do Rio de Janeiro (UFRJ). Pesquisador Associado do Grupo de Economia da Inovação (GEI-IE/UFRJ). E-mail: guilhermedeoliveirasantos.gos@gmail.com

\section{RENATA LÈBRE LA ROVERE}

Universidade Federal do Rio de Janeiro (UFRJ). Instituto de Economia. Professora Titular. Email: renata@ie.ufrj.br

\section{ROBSON DIAS DA SILVA}

Universidade Federal Rural do Rio de Janeiro (UFRRJ/IM). Departamento de História e Economia. Professor Associado 2. E-mail: robsondsilva@gmail.com

\section{VINICIUS LAYTER XAVIER}

Universidade Federal do Rio de Janeiro (UFRJ) Departamento de Estatística, Instituto de Matemática e Estatística. Professor Adjunto. E-mail: viniciuslx@ime.uerj.br 